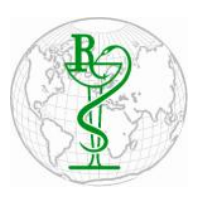

INDO GLOBAL JOURNAL OF

PHARMACEUTICAL SCIENCES

ISSN 2249- 1023

\title{
Recovery of Solvents and Active Ingredients Using Charcoal \& Ultrasonication
}

\author{
Prachet Pinnamaneni ${ }^{*}$, Elphine Prabahar Arulsamy, Venkata Suresh Ponnuru, Geervani Pamidimmari, \\ Sowjanya Koyi, Rama Rao Nadendla
}

Department of Pharmaceutical Analysis, Chalapathi Institute of Pharmaceutical Sciences, Lam, Guntur

\begin{abstract}
Address for Correspondance

Prachet

Pinnamaneni, prachetpinnaman eni@gmail.com

Received:

09.06.2017

Accepted:

06.12.2017

ABSTRACT: The present study aimed to recover the organic solvents and active ingredients as well by using charcoal (adsorption) and (desorption). The process in which molecular species leave the surface of a solid and escape into the surroundings; simply reverse of absorption or adsorption is called as Desorption. Activated carbon was added to the mobile phase Methanol: Water (50:50) which contains active ingredient (Paracetamol) and stirred and centrifuged, the supernatant layer was measured for the absorbance. After confirming the absence of active ingredients in the supernatant the activated carbon loaded with active ingredient was dried under air. 0.1M Sodium hydroxide solution was added to the dried matter and was Ultrasonicated at different calorimetric powers to facilitate desorption of active ingredients. The supernatant shows no absorption maxima at the wavelength of the active ingredient $(257 \mathrm{~nm})$ and peaks were shown in HPLC system after desorption by Ultrasonication. Thus the organic solvent as well as active ingredients can be reused for further studies. The study has huge advantage because of complete recovery of solvents as well as active ingredients. () 2017 iGlobal Research and Publishing Foundation. All rights reserved.
\end{abstract}

Keywords Ultrasound; Adsorption; Desorption; Activated Carbon.

\section{INTRODUCTION}

Desorption is a phenomenon whereby a substance is released from or through a surface. The process is the opposite of sorption (that is, either adsorption or absorption). This occurs in a system being in the state of sorption equilibrium between bulk phase (fluid, i.e. gas or liquid solution) and an adsorbing surface (solid or boundary separating two fluids). When the concentration (or pressure) of substance in the bulk phase is lowered, some of the sorbed substance changes to the bulk state. In chemistry, especially chromatography, desorption is the ability for a chemical to move with the mobile phase. The more a chemical desorbs, the less likely it will adsorb, thus instead of sticking to the stationary phase, the chemical moves up with the solvent front. After adsorption, the adsorbed chemical will remain on the substrate nearly indefinitely, provided the temperature remains low. However, as the temperature rises, so does the likelihood of desorption occurring. The general equation for the rate of desorption is:

$$
R=r N^{x}
$$

where $r$ is the rate constant for desorption, $N$ is the concentration of the adsorbed material, and $\boldsymbol{X}$ is the kinetic order of desorption.

Ultrasonication is the irradiation of a liquid sample with ultrasonic waves resulting in agitation. Sound waves propagate into the liquid media result in alternating highpressure (compression) and low-pressure (rarefaction) cycles. Sonication is the act of applying sound energy to agitate particles in a sample, for various purposes. Ultrasonic frequencies $(>20 \mathrm{kHz})$ are usually used, leading to the process also being known as ultrasonication or ultra-sonication. 
Indo Global Journal of Pharmaceutical Sciences, 2017; 7(2): 148-151

In the laboratory, it is usually applied using an ultrasonic bath or an ultrasonic probe, colloquially known as sonicator.

\section{MATERIALS AND METHODS}

Paracetamol with purity greater than $99.5 \%$ and ultra-high quality (UHQ) water were used to prepare the aqueous solutions. The Granular activated carbon (GAC) has a BET surface area of $929 \mathrm{~m}^{2} \mathrm{~g}^{-1}$ and a mean granulometry of $3 \mathrm{~mm}$. The carbon was pretreated by boiling in ultra-high quality water for $1 \mathrm{hr}$ and washed thoroughly with UHQ water until the UV absorbance intensity was equal to zero. Finally, the washed GAC was dried in an oven at $110^{\circ} \mathrm{C}$ to constant weight before use.

\section{HPLC Instrumentation and Conditions:}

The analysis was carried out on a HPLC system (Agilent 1220) equipped with UV detector, pressure controlled by reciprocating pump and operated by Ezechrome Software. InertsilC18 column $(250 \mathrm{~mm} \times 4.6 \mathrm{~mm}$ i.d., particle size $5 \mu \mathrm{m})$ was used for separation. Mobile phase used for separation was mixture containing methanol and water of HPLC grade (50: $50 \mathrm{v} / \mathrm{v})$. The flow rate was kept at $1.0 \mathrm{ml} / \mathrm{min}$, column temperature was ambient $\left(25^{\circ} \mathrm{C}\right)$, eluents were detected by UV detector at $205 \mathrm{~nm}$, and the injection volume was $20 \mu \mathrm{l}$.

\section{EXPERIMENTAL PROCEDURE:}

\section{RECOVERY OF SOLVENTS:}

\section{Preparation of mobile phase:}

Mobile phase was prepared by mixing 50 volumes of methanol and 50 volumes of water of HPLC grade. The mobile phase was ultrasonicated, filtered through $0.45 \mu \mathrm{m}$ membrane filter, and degassed.

\section{Preparation of Standard Solution:}

Standard stock solution was prepared by weighing accurately $10 \mathrm{mg}$ of paracetamol and dissolved in the $10 \mathrm{ml}$ volumetric flask and made up volume with mobile phase $(1000 \mu \mathrm{g} / \mathrm{ml})$. From the above stock solution $1 \mathrm{ml}$ was taken separately and diluted to $10 \mathrm{ml}$ to obtain a final concentration $100 \mu \mathrm{g} / \mathrm{ml}$.

\section{PROCEDURE:}

Inject $20 \mu 1$ solution into the system and peak was observed, the eluting solvent and active ingredient from column was passed through activated charcoal and the resulting solution was injected into system and there we observe a blank peak which is nothing but mobile phase peak while the active ingredient was desorbed in the charcoal and also the supernatant layer was measured for the absorbance.

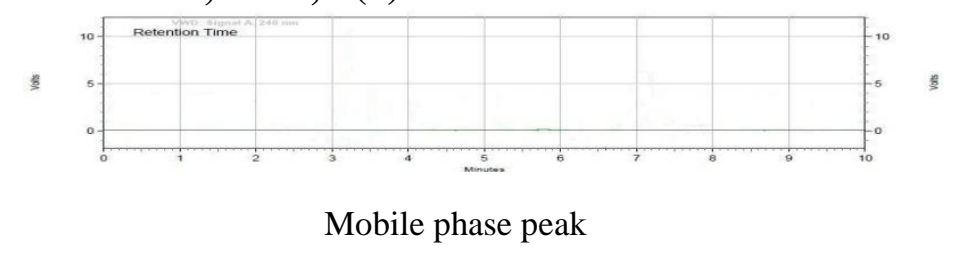

\section{RECOVERY OF ACTIVE INGREDIENTS:}

\section{Preparation of 0.1 M NaOH:}

Weigh accurately $4 \mathrm{gm}$ of sodium hydroxide pellets $(\mathrm{NaOH})$ and dissolved in a $1000 \mathrm{ml}$ volumetric flask to get $0.1 \mathrm{M}$ $\mathrm{NaOH}$.

\section{PROCEDURE:}

After confirming the absence of active ingredients in the supernatant the activated carbon (charcoal) loaded with active ingredientwas dried underair. Now, to the dried active ingredient which is present in the charcoal was taken and to this $0.1 \mathrm{M} \mathrm{NaOH}$ was added to determine their effects on desorption under ultrasonic field at $21 \mathrm{kHz}, 15.2-38.3 \mathrm{~W}, 1 \mathrm{hr}$ irradiation.

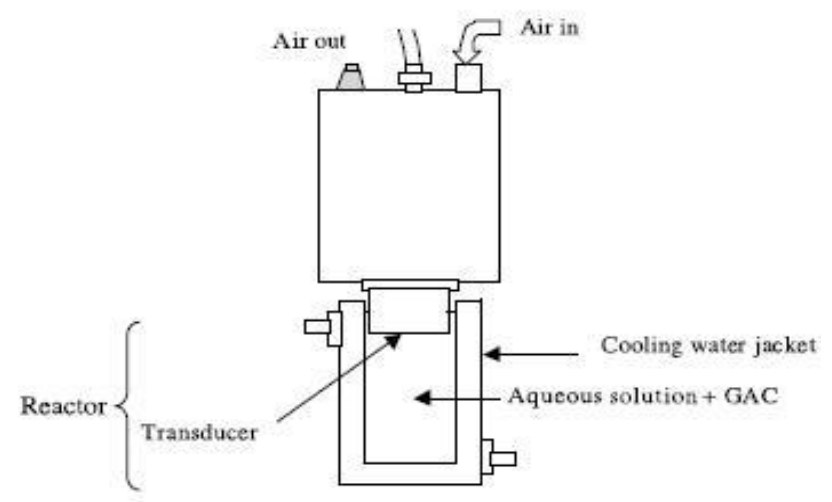

Scheme of the experimental set-up for desorption under ultrasonic field.

Now after the ultrasonication the resulting solution was taken and was injected into the HPLC system, the peak was observed. i.e. paracetamol.

\section{RESULTS AND DISCUSSION}

Paracetamol was well- Advanced resolved using mobile phase composition of methanol and water of HPLC grade $(50: 50 \mathrm{v} / \mathrm{v})$ at flow rate of $1 \mathrm{ml} / \mathrm{min}$, UV detection wavelength $205 \mathrm{~nm}$ and injection volume was $20 \mu 1$. The HPLC system was found to best for analysis.

\section{METHOD VAIDATION:}

As per ICH guidelines, the method validation parameters checked were specificity, linearity, precision, accuracy, limit of detection, limit of quantitation and robustness. 


\section{Indo Global Journal of Pharmaceutical Sciences, 2017; 7(2): 148-151}

\section{Specificity}

A blank solution (mobile phase) was injected and the chromatogram showed no inferring peaks at retention time of the drug. The chromatogram of paracetamol extracted from the tablet were compared with those acquired from paracetamol standard, correlation was good (in terms of Rt and area) indicates specificity of method. Common tablet excipients like starch, lactose, magnesium stearate were dispersed in mobile phase, filtered and injected. There was no interference found.

\section{Linearity and range}

Aliquots of standard solutions of paracetamol were taken in 10 $\mathrm{ml}$ volumetric flasks and diluted with mobile phase to get final concentrations in best fit range for paracetamol. Triplicate injections were made five times for each concentration separately and chromatographed under the conditions as described above. The plots of peak area versus respective concentrations of paracetamol were found to be linear in the concentration range.

\section{Precision}

Precision study was performed to find out intra-day and interday variations. The percent relative standard deviation for intra-day precision was $99 \%$ for paracetamol and inter-day precision was $98 \%$ for paracetamol. Both the values were well within the limit of $2 \%$ as per ICH guidelines.

\section{Accuracy}

The accuracy was determined by recovery studies. The recovery studies were performed by standard addition method, at $80 \%, 100 \%, 120 \%$ level. Percent recovered was calculated using regression equation. The percentage recovery were calculated.

\section{Limit of detection}

The limit of detection (LOD) is the smallest concentration that can be detected but not necessarily quantified as an exact value.

\section{Limit of quantitation}

The limit of quantification (LOQ) is the lowest amount of analyte in the sample that can be quantitatively determined with suitable precision and accuracy.

\section{Robustness}

Robustness of the method was determined by making slight deliberate changes in chromatographic conditions like $1 \%$ change in ratio of mobile phase constituents, $1 \mathrm{~nm}$ change in detection wavelength and $0.05 \%$ change in flow rate. It was observed that there were no marked
Changes in the chromatogram. It suggests that the developed method is robust.

\section{CONCLUSION}

In this work the feasibility for the use of ultrasound for desorption of paracetamol from activated carbon. Both types of sorbents showed an enhancement in desorption rate in the presence of ultrasound at $40 \mathrm{kHz}$ that was greater than that observed in the nonsonic case. However, activated carbon showed a tendency to be pulverized under the action of ultrasound at $40 \mathrm{kHz}$. At a higher frequency of $1.44 \mathrm{MHz}$, the pulverization of carbon was prevented and a sufficient enhancement in desorption rate was obtained. Hence the developed RP-HPLC method for the determination of paracetamol can be used for routine analysis of dosage form.

\section{REFERENCES}

[1] Desorption by Ultrasound: Phenol on Activated Carbon and Polymeric Resin Salil U. Rege and Ralph T. Yang Dept. of Chemical Engineering, Charles A. Cain Dept. of Biomedical Engineering, University of Michigan, Ann Arbor, MI 48109.

[2] Effects of ultrasound on adsorption-desorption of p-chlorophenol on granular activated carbon, O. Hamdaoui a, E. Naffrechoux b, ${ }^{*}, \mathrm{~L}$. Tifouti a, C. P_etrier a Department of Process Engineering, Faculty of Engineering, University of Annaba, P.O. Box 12, 23000 Annaba, Algeria, b Laboratoire de ChimieMol_eculaire et Environment, ESIGEC, Universit_e de Savoie, BP 1104, 73376 Le Bourget du Lac Cedex, France Received 17 June 2002; accepted 23 September 2002.

[3] J.L. Sotelo, G. Ovejero, J.A. Delgado, I. Martinez, Comparison ofadsorption equilibrium and kinetics of four chlorinated organicsfrom water onto GAC, Water Res. 36 (2002) 599-608.

[4] D.M. Nevskaia, A. Santianes, V. Munoz, A. GuerreroRuiz,Interaction of aqueous solutions of phenol with commercialactivated carbons: an adsorption and kinetic study, Carbon 37(1999) 1065-1074.

[5] G. McKay, M.J. Bino, A. Altememi, External mass transferduring the adsorption of various pollutants onto activated carbon,Water Res. 20 (1986) 435-442

[6] Solvent Extraction and Related Studies on Silver Recovery from Aqueous Solutions, A.P paiva Pages 947-1008

[7] Eskelund, G. R.; Wu, K. K.; Rosenblatt, D. H.; Davis, S.T.; Demek, M. M.; Dennis, W. H., Jr., "A Laboratory Studyof Carbon Adsorption for Elimination of Nitrobody Waste from Army Ammunition Plants", Picatinny Arsenal, Dover, NJ, 1973, AMCMS 4932.05 .4114$.

[8] Demek, M. M.; Davis, G. T.; Richmond, . A.; Sommer, H.Z.; Rosenblatt, D. H.; Eskelund, G. R., "Studies on theRegeneration of Activated Carbon for the, Removal of a-TNT from Waste Waters", Edgewood Arsenal, Atuerdeen Proving Ground, MD, 1974, EC-TR74008.

[9] Adamson, A. W., "Physical Chemistry of Surfaces", $4^{\text {th }}$ Ed., Wiley, New York, NY, 1982.

[10] Hoffmann, M. R., I. Hua, and R. Hochemer, "Applications of Ultrasonic Irradiation for the Degradation of Chemical Contaminants in Water," UltrasonicsSonochem.,3, S163 (1996). 
Indo Global Journal of Pharmaceutical Sciences, 2017; 7(2): 148-151

[11] Recasens, F., B. J. McCoy, and J. M. Smith, "Desorption Processes: Supercritical Fluid Regeneration of Activated Carbon," AlChE J., 35: 951 (1989).

[12] Winkler, K., K.-H. Radeke, and H. Stach, "Adsorption/Desorption Behavior of Organic Water Pollutants onto an Adsorber Polymer,"Chem. Tech. (Leipzig), 48, 249 (1996).

[13] Hutchinson, D. H., and C. W. Robinson, "A Microbial Regeneration Process for Granular Activated Carbon," Water Res., 24, 1209(1996).

Indo Global Journal of Pharmaceutical Sciences( ISSN 22491023 ; UGC Journal No.: 44477; CODEN- IGJPAI; NLM ID: 101610675) indexed and abstracted in EMBASE(Elsevier), UGC Journal List, National Library of Medicine (NLM) Catalog, Elsevier( EMBASE), ResearchGate, Publons, CAS (ACS), Index Copernicus, Google Scholar and many more. For further details, visit http://iglobaljournal.com 